\title{
CLINICAL OUTCOMES OF POMPEDO VERSUS NUSMILE (NSZ) CROWNS. A RETROSPECTIVE COHORT STUDY
}

\author{
Ahmed Elkhadem*
}

\begin{abstract}
Restoration of badly decayed primary incisors is challenging. Esthetics crowns present a solution to this problem. Pompedo esthetic crown is made of polyoxymethylene. The clinical performance of Pompedo crowns have not been tested before. Thus, the aim of this study is to compare the effectiveness of Pompedo (PC) versus NuSmile zirconia crowns (NSZ) in terms of retention, discoloration and fracture. Methods: Records from a private practice was screened for children conforming with eligibility criteria. Twelve children in both groups were recalled for follow-up. Two assessors examined the children and the records. Consensus resolved differences between examiners.
\end{abstract}

Results: The relative risk for crown dislodgement was 1.25 (95\% CI: 0.4 to 3.8), with no significant statistical difference $(\mathrm{P}<0.05)$. The relative risk for crown discolouration was 2.43 (95\%CI: 0.67 to 8.85 ) with one and a half time more chance for crown discolouration in PC compared to NSZ, but this result is not statistically significant $(\mathrm{P}<0.05)$. Finally, the risk of crown fracture in the NSZ was $8 \%$ (95\% CI: 3 to 18 ), while none of the PC was broken.

Conclusion: In conclusion, both NSZ and PC showed good clinical performance with NSZ slightly better in resisting colour changes and PC being better in resisting crown fracture. PC can be recommended for use as an aesthetic replacement for zirconia crowns in primary teeth due to its lower cost and comparable clinical performance over two years post placement

KEYWORDS: NuSmile crown, Pompedo crown, Esthetic anterior crown, Dental caries.

\section{INTRODUCTION}

Dental caries is the primary reasons for restoring primary incisor teeth in young children. The development of carious lesions in primary maxillary incisors is often related to night-time breast or baby bottle, and the consumption of a high content sugar diet after weaning ${ }^{1}$.
The premature loss of primary maxillary incisors leads to esthetic, functional and pronunciation problems. The perception of esthetics has increased between parents. Some of them feel devastated by the appearance of their children with missed maxillary incisors. Moreover, child teasing due to loss of upper teeth can result in possible

\footnotetext{
* Lecturer, Pediatric Dentistry Department, Faculty of Oral \& Dental Medicine, Cairo University.
} 
psychological problems for the child. Although there is no quantitative research regarding the effect of loss of upper incisors on biting efficiency, it is expected to have a problem regarding eating hard food. The child would compensate this by chewing on posterior teeth unilaterally, which could affect the TMJ on the opposite side. Finally, the pronunciation of tongue-tip consonants ('t', 'd', 's', 'sh' and 'ch'), and the labial sounds of ' $\mathrm{f}$ ' and ' $\mathrm{v}$ ' are expected to be compromised by the absence of upper incisors ${ }^{2}$. Thus, the restoration of primary maxillary incisors became of prime importance.

The restoration of badly carious primary teeth can be challenging. In many cases, more than half of the tooth structure is destroyed, and in some instances, the carious margin flushes with the gingival one. Previous techniques to restore these teeth aimed to increase retention using intra-radicular elements. Examples of these techniques are composite resin short post $^{3,4}$, indirect composite resin reinforced with fibreglass posts ${ }^{2}$ and steel loops for intraradicular retention ${ }^{5}$. In the past decade, the use of prefabricated incisor crowns increased between pediatric dentists as they required less procedural steps. In many instances, the clinician will apply the crown without the need for retentive intra-radicular means.

One common crown used in Egypt is Nusmile zirconia one. A drawback of these crowns is the high cost. Thus, an alternative cheaper crown was developed by CAD-CAM technology and was called Pompedo crown. This study follows a null hypothesis, i.e. there will be no difference in retention, crown discolouration and crown fracture between Pompedo and NuSmile crowns.

\section{Aim of the study}

This study seeks to compare the retention, discolouration and fracture of NuSmile zirconia crown versus a new designed CAD CAM milled crown (Pompedo) in children with decayed maxillary incisors.

\section{PICO format:}

Population: Children with carious maxillary upper incisors

Intervention: Pompedo crown (CAD-CAM milled crowns)

Control: Nusmile zircon crowns (NSZ)

\section{Outcome:}

\begin{tabular}{|l|l|l|}
\hline \multicolumn{1}{|c|}{ Outcome } & \multicolumn{1}{|c|}{ Measuring device } & $\begin{array}{c}\text { Measuring } \\
\text { unit }\end{array}$ \\
\hline 1. Crown dislodgement & Visual inspection/record & Binary \\
\hline 2. Crown discoloration & Visual inspection & Binary \\
\hline 3. Crown fracture & Visual inspection/record & Binary \\
\hline
\end{tabular}

Time: 2 years follow-up.

\section{MATERIALS AND METHODS:}

This trial is a practice based retrospective cohort study with allocation ratio $1: 1$. The unit of measurement is the crown. Eligibility criteria were children with carious maxillary upper central and lateral incisors bilateral. The child should not exceed four years of age to avoid the tooth being lost due to shedding. All the procedures should have been carried out under general anaesthesia to ensure that child behaviour did not affect the outcome.

In June 2017, the patient records in a pediatric dentistry practice at Cairo, Egypt were searched from January to June 2015 for children that match inclusion and exclusion criteria. The upper incisor crowns could be either Pompedo or NuSmile crowns. Parents of patients were called for a followup of the crowns.

All children were treated by the same operator (A.E). After administration of general anaesthesia, caries was removed using high-speed diamond stone. If pulp was exposed, pulpectomy was carried out, and root was filled by zinc oxide/eugenol mix till the level of the orifice. The crowns of the maxillary incisors were prepared to receive either 
Pompedo or Nusmile® ZR (Houston, Texas, USA) crowns (Figures 1,2). The preparation extends 1 to $1.5 \mathrm{~mm}$ subgingival to increase the retention of the crown. NuSmile crown preparation required more extensive preparation to eliminate any undercuts.

The trial fit of the crown differed between Pompedo and NuSmile. In NuSmile crowns, pink crowns are utilised (Figure 1). These crowns have

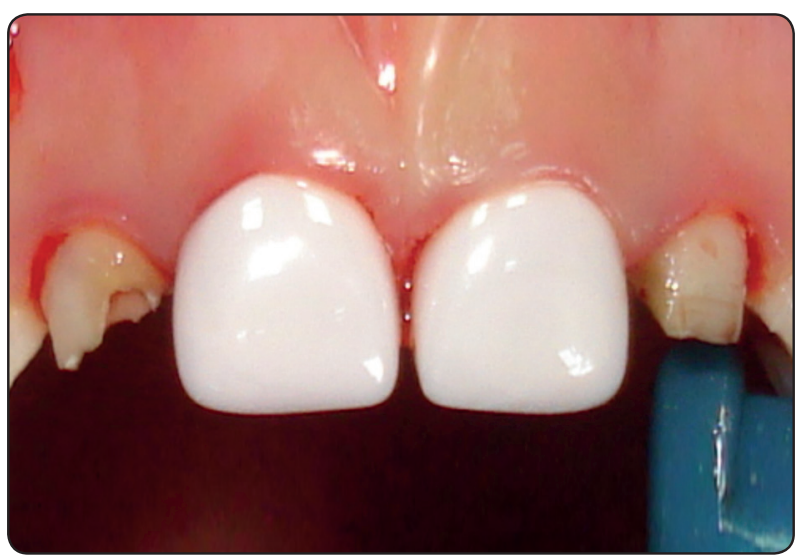

Fig. (1) Pink trial crown for NSZ following teeth preparation. Note the slight gingival bleeding following subgingival reduction. the same contour as the zircon crowns. They are used to prevent contamination of the fitting surface of the NuSmile zircon crown. Hence, results in better bond strength. On the contrary, Pompedo crowns are used for the trial fit. The adhesive surface of the crown is thoroughly washed with airwater spray for 10 seconds to remove any blood or saliva contaminants; then air dried till becoming chalky white. This ensures that the sandblasted inner surface is decontaminated.

Before cementation, the four incisor crowns are fitted together to ensure proper alignment and articulation with opposing teeth. Pompedo and NuSmile crowns were cemented using Riva (SDI, Victoria, Australia), which is a self-cure glass ionomer luting cement. Excess cement was removed three minutes after cementation using a probe labial and lingual. Dental floss was used to remove excess cementation interproximal.

Following the crown cementation, the parents and the child were instructed to avoid sticky food, biting solid objects and fighting with peers.

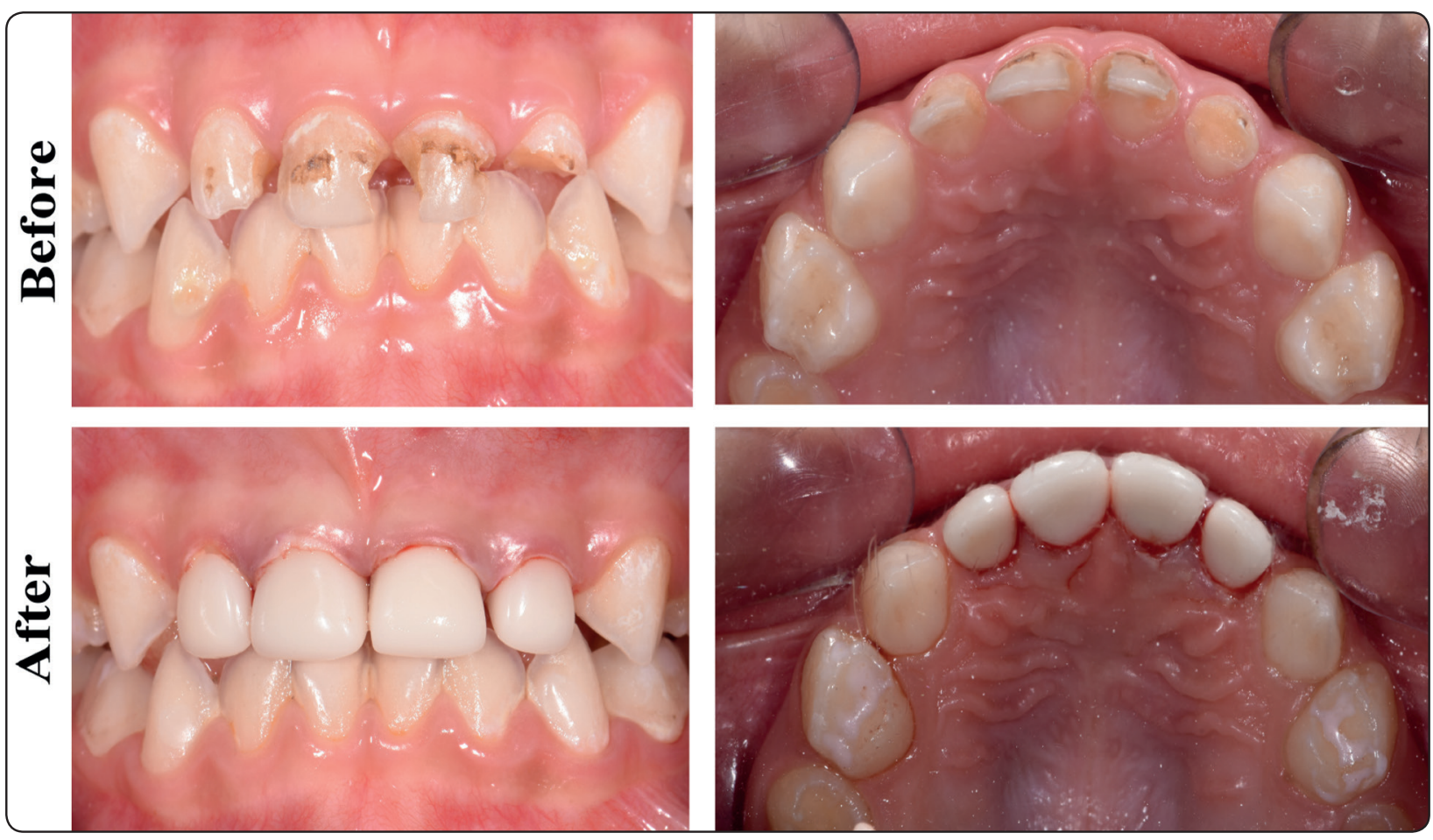

Fig. (2) Frontal and occlusal views for Pompedo crowns placed on primary maxillary incisors 


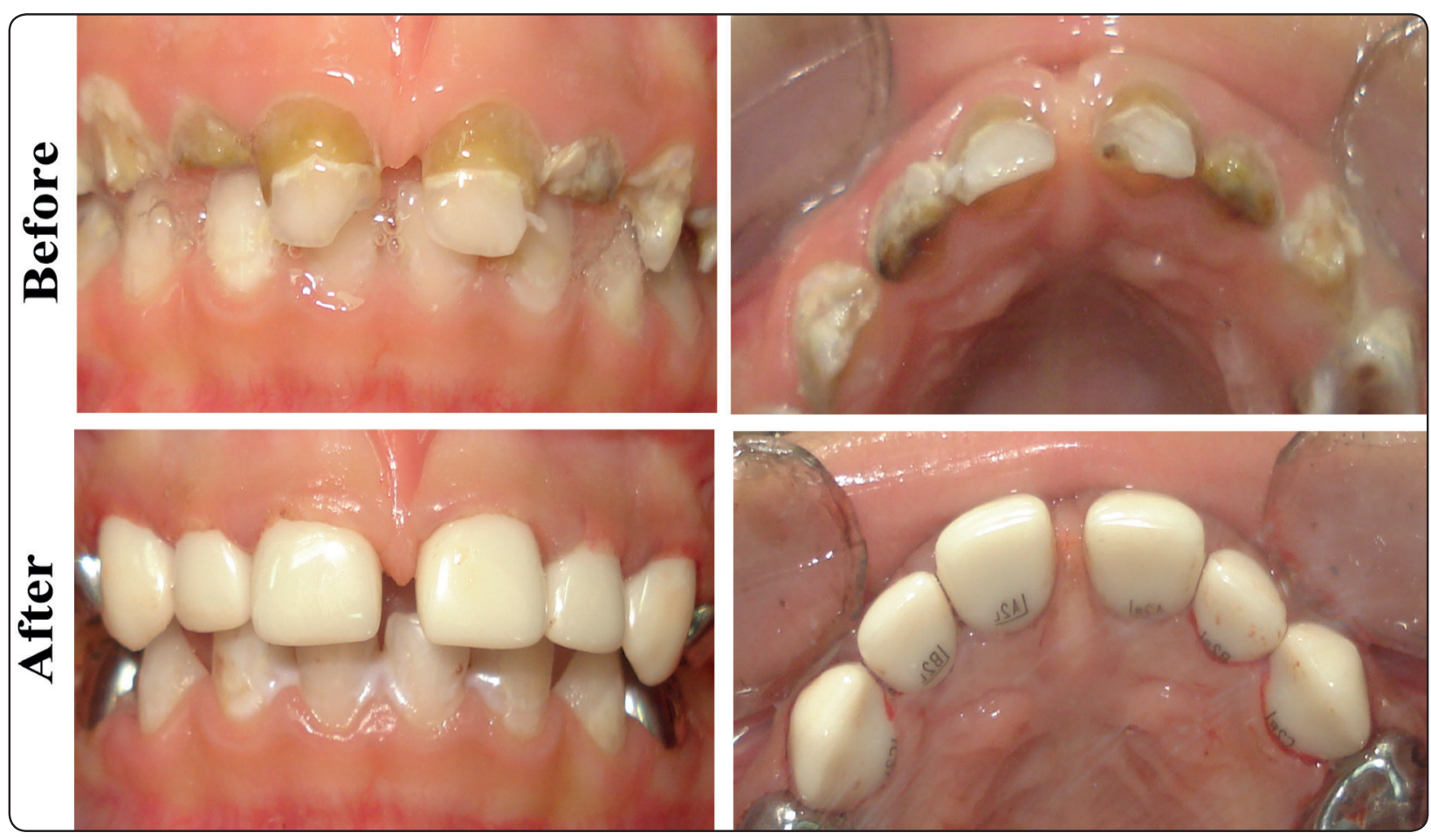

Fig. (3) Frontal and occlusal views for NuSmile crowns placed on primary maxillary incisors

The gingival tissue is slightly injured due to the subgingival reduction for crown preparation. The parents were instructed to keep good oral hygiene measure using a soft toothbrush at least twice daily. The gingival tissue is supposed to heal within two weeks interval.

On the day of recall, two assessors examined the children and the records. Each assessor reviewed the child separately. Crown was checked for its presence, colour and fracture. The child record is examined for a previous history of crown dislodgment or fracture that has been managed. Consensus resolved differences between examiners.

\section{RESULTS}

Data items for demographics of selected children are (Table 1):

- Number of children included,

- The total number of the crown placed for all children,

- The mean age of children at the day of operation under general anaesthesia,
- The age range,

- The mean time elapsed between the surgery day and the follow-up recall,

- The number of males and females, and

- The number of teeth subjected to pulpectomy at the operation before crown placement.

TABLE (1) Baseline characteristics of children in Pompedo and NuSmile groups:

\begin{tabular}{|l|l|l|}
\hline & Pompedo group & NuSmile group \\
\hline Number (child) & 12 & 12 \\
\hline Number (crown) & 48 & 50 \\
\hline Mean age (at operation day) & 3 years 4 months & 3 years 6 month \\
\hline Age range (years) & 2.5 to 4 & 2.7 to 4.2 \\
\hline Follow-up (at recall day) & 2 years 4 month & 2 years 2 month \\
\hline Males & 5 & 6 \\
\hline Females & 7 & 6 \\
\hline $\begin{array}{l}\text { Number of } \\
\text { pulpectomies (tooth) }\end{array}$ & 24 & 38 \\
\hline
\end{tabular}




\section{Crown dislodgement:(Table 2)}

The risk of crown dislodgment for Pompedo group was $12.5 \%$ (95\% CI: 5.8 to 24.7 ), while that of NuSmile crown was $10 \%$ (95\% CI: 4.3 to 21.4). The relative risk was 1.25 (95\% CI: 0.4 to 3.8). Thus, there is $25 \%$ more chance of crown dislodgement in Pompedo versus NuSmile, but this result is not statistically significant $(\mathrm{P}<0.05)$.

TABLE (2) Results of crown dislodgement, discoloration and fracture

\begin{tabular}{|l|c|c|}
\hline \multicolumn{1}{|c|}{ Outcome name } & $\begin{array}{c}\text { Pompedo } \\
(\mathrm{n}=48)\end{array}$ & $\begin{array}{c}\text { NuSmile } \\
(\mathrm{n}=50)\end{array}$ \\
\hline 1. Crown dislodgment & 6 & 5 \\
\hline 2. Crown discoloration & 7 & 3 \\
\hline 3. Crown fracture & 0 & 4 \\
\hline
\end{tabular}

\section{Crown discolouration:}

The risk of crown discolouration for Pompedo group (Figure 4) was 14\% (95\% CI: 7 to 27), while that of the NuSmile zirconia crown was $6 \%(95 \%$ CI: 2 to 16). The relative risk was 2.43 (95\%CI: 0.67 to 8.85 ). Thus, there is one and a half time more chance for crown discolouration in Pompedo crown compared to NuSmile zircon crown, but this result is not statistically significant $(\mathrm{P}<0.05)$.

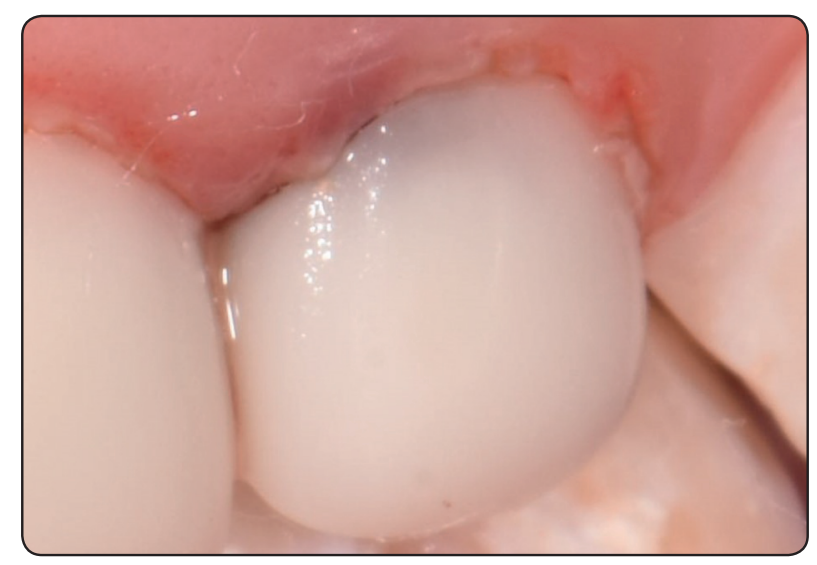

Fig. (4) Discoloration at the labial margin of Pompedo upper lateral primary incisor

\section{Crown fracture:}

The risk of crown fracture in the NuSmile crown was $8 \%$ (95\% CI: 3 to 18). None of the Pompedo crowns was fractured.

\section{DISCUSSION}

The demand for esthetics increased in the past decade. This market needs has transferred from the treatment of permanent teeth to the primary ones.

The parent's concern about the looks of their children during smiling became of prime importance. Thus, the anterior esthetic crown is a standard restoration among pediatric dentists ${ }^{6}$.

Pompedo crown is made of polyoxymethylene (POM). This material had various uses in the dental field especially in orthodontics and prosthetic dentistry. In orthodontics, it is used to fabricate esthetic polymer brackets since $1997^{7}$ with surpassing mechanical properties ${ }^{8}$. In prosthetic dentistry, it has been used as a denture base material, esthetic denture clasp and as an interim fixed implant-supported prosthesis ${ }^{9,10,11}$. These dental applications encouraged the design and fabrication of pediatric crowns made of POM. The privilege of such crowns would be the minimised cost compared to the readily available zircon crowns in the market. Thus, this cohort study aimed to investigate the effectiveness of Pompedo crown versus NuSmile Zircon crown.

Baseline characteristics table shows that there are minimal differences between Pompedo and $\mathrm{NuSmile}$ group regarding mean age, male to female ratio and mean follow-up. On the contrary, there was a difference in the number of teeth having pulpectomy in NuSmile group $(n=38)$ compared to Pompedo group $(n=24)$. This difference could be attributed to the increase in preparation for the NuSmile crown to reach a full crown fit with the elimination of all undercuts. When the reduction increases, there is a greater chance to encroach on the pulp space with subsequent need for pulp 
therapy. One advantage of Pompedo crown was its resilience. Hence, the crown can be pressed upon without fear of breakage. Also, the crown can embrace an undercut. Thus, tooth reduction can be minimised with more tendency for preserving the pulp uninjured. All patients in Pompedo and NuSmile groups had four incisor crowns. Only one patient in NuSmile had two extra crowns for the primary canines (Figure 3 ).

Crown retention can be affected by the technique of cementation, saliva and blood contamination, the bond strength between luting cement and the inner surface of the crown, amount of remaining tooth structure and being subjected to external factors like sticky food and traumatic blow. In this study, the crown retention was nearly similar in both Pompedo and NuSmile crown with no statistically significant difference. The failure rate in crown retention was comparable to stainless steel crowns and preveneered stainless steel crown in posterior primary teeth $^{12}$.

Saliva contamination on the luting surface of zirconia adversely affects resin bonds to zirconia ceramic and its durability ${ }^{13}$. Hence, the NuSmile company invented pink crowns to be used in trial fitting before the final insertion of the zirconia crown. But it should be noted that these pink trial crowns tend to break easily under pressure, which means that the practitioner should have more than one pink crown in each size to compensate the broken ones. Further, these pink crowns are relatively expensive which adds up to the cost of the zirconia crown.

On the contrary, the inner surface of Pompedo crowns is sandblasted. Any salivary contamination could be easily washed out from the fitting surface of the crown using air-water spray. Then, air dryness of the crown inner surface till chalky white appearance is visible. Air dryness is crucial as it increases the surface area of contact between the luting cement and fitting surface of the crown. Adversely, water film could interfere with this bond with subsequent loss of retention.
Regarding crown discolouration, NuSmile zircon crown was superior compared to Pompedo one. Crown discolouration or colour change was detected compared to adjacent crowns and crowns present in stock. Although POM block is opaque, the thin cervical margin produced after $\mathrm{CAD} / \mathrm{CAM}$ milling is slightly translucent. During cementation, the inner surface of the crown can be contaminated with blood. Following blood impregnation, hemolysis of red blood cells occurs releasing haemoglobin or other hematin molecules with subsequent release of iron ions. These ions can react with sulphates produced by bacteria and produce ferric sulphate $(\mathrm{FeS})^{14}$. Due to the dark brown-red hue of this compound, discolouration subsequently occurs creating a brownish hue at the cervical margin of the crown. It is not uncommon to find cases on the internet discussing the presence of discolouration problem with zirconia crowns in permanent dentition ${ }^{15}$.

The issue of crown discolouration can be minimized by preventing blood contamination during cementation. Thus, the practitioner should carry out the cementation after complete cessation of bleeding. Hence, in full mouth rehabilitation for children, it is recommended to start preparation of incisor teeth, finish the trial insertion and adjustments, then cement the crown after treatment of the rest teeth in the mouth. This sequence would ensure that gingival bleeding has stopped. The use of hemostatic agents is not recommended as they contain iron. Iron can easily impregnate to tooth substance because of its high affinity to porous dentin with the subsequent darker appearance of the crown ${ }^{15}$.

As for crown fracture, Pompedo crown was superior over NuSmile zircon crown which suffered $8 \%$ failure over two years follow-up. Fracture of pre-veneered crowns has been reported with the rate reaching up to $12 \%$ over one year followup $^{16}$. It should be noted that the forces required to 
break the pre-veneered stainless-steel crowns were greater than the forces needed to fracture zirconia crowns ${ }^{17}$. Meanwhile, none of the Pompedo crowns suffered fracture over two years follow-up. This can be attributed to the high modulus of elasticity and resistance to impact and fatigue of POM that prevents its fracture under cyclic loading ${ }^{18}$.

In conclusion, both $\mathrm{NuSmile}$ zirconia crown and Pompedo showed good clinical performance with NuSmile slightly better in resisting colour changes and Pompedo being better in resisting crown fracture. Pompedo can be recommended for use as an aesthetic replacement for zirconia crowns in primary teeth due to its lower cost and comparable clinical performance over two years post placement.

\section{REFERENCES}

1. Ripa LW. Nursing caries: a comprehensive review. Pediatr Dent 1988, 10(4): 268-282.

2. Motisuki C, Santos-Pinto L, Giro EM. Restoration of severely decayed primary incisors using indirect composite resin restoration technique. Int J Paediatr Dent 2005, 15(4): 282-286.

3. Mendes FM, De Benedetto MS, del Conte Zardetto CG, Wanderley MT, Correa MS. Resin composite restoration in primary anterior teeth using short-post technique and strip crowns: a case report. Quintessence Int 2004, 35(9): 689-692.

4. Judd PL, Kenny DJ, Johnston DH, Yacobi R. Composite resin short-post technique for primary anterior teeth. J Am Dent Assoc 1990, 120(5): 553-555.

5. Mortada A, King NM. A simplified technique for the restoration of severely mutilated primary anterior teeth. J Clin Pediatr Dent 2004, 28(3): 187-192.

6. Oueis H, Atwan S, Pajtas B, Casamassimo PS. Use of anterior veneered stainless steel crowns by pediatric dentists. Pediatr Dent 2010, 32(5): 413-416.

7. Foerster R, inventor Plastic orthodontic bracket for retaining wire bridge with projections of second plastic. 1997.
8. Krauss J, Faltermeier A, Behr M, Proff P. Evaluation of alternative polymer bracket materials. Am J Orthod Dentofacial Orthop 2010, 137(3): 362-367.

9. Gomez-Polo M, Gomez-Polo C, Del Rio J, Ortega R. Stereophotogrammetric impression making for polyoxymethylene, milled immediate partial fixed dental prostheses. J Prosthet Dent 2017.

10. Fitton JS, Davies EH, Howlett JA, Pearson GJ. The physical properties of a polyacetal denture resin. Clin Mater 1994, 17(3): 125-129.

11. Ata SO, Yavuzyilmaz H. In vitro comparison of the cytotoxicity of acetal resin, heat-polymerized resin, and autopolymerized resin as denture base materials. J Biomed Mater Res B Appl Biomater 2009, 91(2): 905-909.

12. Lopez-Loverich AM, Garcia MM, Donly KJ. Retrospective Study of Retention of Stainless Steel Crowns and Preveneered Crowns on Primary Anterior Teeth. Pediatr Dent 2015, 37(7): 530-534.

13. Yang B, Lange-Jansen HC, Scharnberg M, Wolfart S, Ludwig $\mathrm{K}$, Adelung $\mathrm{R}$, et al. Influence of saliva contamination on zirconia ceramic bonding. Dent Mater 2008, 24(4): 508-513.

14. Marin PD, Bartold PM, Heithersay GS. Tooth discoloration by blood: an in vitro histochemical study. Endod Dent Traumatol 1997, 13(3): 132-138.

15. Brady L. All porcelain crown discolration after seating. 2011 [cited] Available from: https://leeannbrady.com/ esthetic-dentistry/all-porcelain-crown-discoloration-afterseating

16. MacLean JK, Champagne CE, Waggoner WF, Ditmyer MM, Casamassimo P. Clinical outcomes for primary anterior teeth treated with preveneered stainless steel crowns. Pediatr Dent 2007, 29(5): 377-381.

17. Townsend JA, Knoell P, Yu Q, Zhang JF, Wang Y, Zhu $\mathrm{H}$, et al. In vitro fracture resistance of three commercially available zirconia crowns for primary molars. Pediatr Dent 2014, 36(5): 125-129.

18. MatWeb. POM Engineering Property Data. Material property data [cited]Available from: http://www.matweb.com/ reference/acetalpolymer.aspx. 